\title{
Toward Safe Pharmacotherapy: The Interplay between Meropenem and Parenteral Nutrition Admixtures
}

\author{
Aleksandra Gostyńska, Ludwika Piwowarczyk, Malwina Nadolna, Anna Jelińska, Katarzyna Dettlaff (D, \\ Magdalena Ogrodowczyk, Maria Popielarz-Brzezińska and Maciej Stawny *D
}

check for updates

Citation: Gostyńska, A.; Piwowarczyk, L.; Nadolna, M.; Jelińska, A.; Dettlaff, K.; Ogrodowczyk, M.; PopielarzBrzezińska, M.; Stawny, M. Toward Safe Pharmacotherapy: The Interplay between Meropenem and Parenteral Nutrition Admixtures. Antibiotics 2021, 10, 217. https://doi.org/ 10.3390/antibiotics10020217

Academic Editor: Jian Li

Received: 18 January 2021

Accepted: 19 February 2021

Published: 22 February 2021

Publisher's Note: MDPI stays neutral with regard to jurisdictional claims in published maps and institutional affiliations.

Copyright: (c) 2021 by the authors. Licensee MDPI, Basel, Switzerland. This article is an open access article distributed under the terms and conditions of the Creative Commons Attribution (CC BY) license (https:/ / creativecommons.org/licenses/by/ $4.0 /)$.
Department and Chair of Pharmaceutical Chemistry, Poznan University of Medical Sciences, 6 Grunwaldzka, 60-780 Poznań, Poland; gostynska.aleksandra@spsk2.pl (A.G.); ludwika.piwowarczyk@wp.eu (L.P.); malwina_nadolna125@interia.pl (M.N.); ajelinsk@ump.edu.pl (A.J.); dettlaff@ump.edu.pl (K.D.); mogrodo@ump.edu.pl (M.O.); mpopiel@ump.edu.pl (M.P.-B.)

* Correspondence: mstawny@ump.edu.pl; Tel.: +48-61-854-66-46

\begin{abstract}
Simultaneous administration of parenteral nutrition (PN) admixtures with intravenous antibiotics is a common clinical problem. Coadministration of drugs incompatible with PN admixture may affect its stability, especially in the context of lipid droplet size, which is a crucial parameter for patient safety. In the present study, we investigate the in vitro compatibility of meropenem (Meropenem 1000, MPM) with five commercial PN admixtures used worldwide: Kabiven, Olimel N9E, Nutriflex Lipid Special, Nutriflex Omega Special, and SmofKabiven. The appropriate volumetric ratios, reflecting their clinical practice ratios, were used to prepare the MPM-PN admixture samples. Physicochemical properties of MPM-PN admixtures samples were determined upon preparation and after four hours of storage. The $\mathrm{pH}$ changes for all MPM-PN admixtures samples did not exceed the assumed level of acceptability and ranged from 6.41 to 7.42. After four hours of storage, the osmolarity changes were $\pm 3 \%$, except MPM-Olimel N9E samples, for which differences from $7 \%$ to $11 \%$ were observed. The adopted level of acceptability of changes in zeta potential after four hours of storage $( \pm 3 \mathrm{mV})$ was met for MPM-Kabiven, MPM-Nutriflex Lipid Special, and MPM-Nutriflex Omega Special. The mean droplet diameter for all samples was below $500 \mathrm{~nm}$. However, only in the case of Nutriflex Lipid Special and Nutriflex Omega Special, the addition of MPM did not cause the formation of the second fraction of lipid droplets. The coadministration of MPM via Y-site with Kabiven, Olimel N9E, and Smofkabiven should be avoided due to osmolarity fluctuations (MPM-Olimel), significant differences in zeta potential (MPM-Olimel, MPM-Smofkabiven), and the presence of the second fraction of lipid droplets $>1000 \mathrm{~nm}$ (MPM-Kabiven, MPM-Olimel, and MPM-Smofkabiven). The assumed acceptance criteria for MPM compatibility of MPM with PN admixtures were met only for Nutriflex Lipid Special and Nutriflex Omega Special in 1:1, 2:1, and 4:1 volume ratios.
\end{abstract}

Keywords: safe pharmacotherapy; meropenem; Y-site administration; parenteral nutrition; drug compatibility

\section{Introduction}

The simultaneous administration of drugs is a frequent clinical practice. This procedure applies to patients with a limited number of vascular accesses or patients in whom the insertion of subsequent vascular accesses is impossible or inadvisable [1]. Such a situation is common in intensive care units where patients need complex pharmacotherapy, including parenteral nutrition and antibiotics administration. Meropenem (MPM) is an antibiotic reserved for the treatment of severe infections. It belongs to the beta-lactams, carbapenem group, and it acts by inhibiting the synthesis of the bacterial cell wall by attaching to penicillin-binding protein (PBP). This antibiotic is resistant to the action of beta-lactamase and renal dehydropeptidase I. MPM, after intravenous administration, binds to plasma proteins in $2 \%$ and distributes to the lungs, bile, skin, muscles, the peritoneal cavity, and 
the cerebrospinal fluid. Due to the wide range of antibacterial effect on both gram-positive (Streptococcus agalactiae, Enterococcus faecalis, Staphylococcus aureus, Streptococcus pneumoniae, Clostridium perfringens) and gram-negative (Escherichia coli, Haemophilus influenzae, Klebsiella pneumoniae, Serratia pneumoniae) bacteria, it is commonly used to treat different serious infections in critically ill patients.

The use of the Y-site for the simultaneous administration of intravenous drugs and parenteral nutrition (PN) is not recommended if there is a lack of data supporting its safety. Such an administration may endanger patients' health and life due to the possibility of interaction between the drug and the PN admixture. It was previously shown that the absence of data confirming the compatibility of two coadministered drugs via the intravenous route leads to high risk of improper administration [2,3]. The most frequent interactions involved drug or PN admixture ingredient precipitation, the formation of large lipid droplets exceeding the critical acceptance limit for intravenous administration, loss of homogeneity of the oil-in-water system, or color change. Such incompatibilities were reported in previous studies [4-15] (Table 1). Interpretation of the results of drugPN compatibility tests and their adaptation into clinical practice should be based not only on the conclusion whether the drug is or is not compatible with PN admixture, but also involve a detailed analysis of the pharmaceutical preparation of the drug $(\mathrm{pH}$, excipients, solubilizers), the composition of the PN admixture (electrolyte content, type of lipid emulsion), and its physicochemical properties ( $\mathrm{pH}$, osmolarity) [2,16-18].

The concept of PN, developed in the 1960s by Professor Stanley Dudrick, assumes the simultaneous supply of all nutrients from one container. PN therapy can be implemented in two ways, namely, compounded PN admixtures or ready-to-use (RTU) PN admixture produced by the pharmaceutical industry. The first solution, i.e., a compounded PN admixture, is most often used in relation to long-term parenterally fed patients who require adjusting their composition to clinical conditions and obligatorily in pediatric and neonatal patients. The remaining patients who require $\mathrm{PN}$ admixture administration receive the most commonly RTU PN mixtures produced in a wide range of compositions and volumes. They can meet the energy and nutritional needs of most patients. Compatibility studies concerning RTU, commercially produced PN admixtures are versatile and clinically useful due to the worldwide availability of such preparations and their more frequent use than compounded PN admixtures.

In the present study, we investigate the in vitro compatibility of meropenem (Meropenem 1000, MPM) with five commercial PN admixtures used worldwide: Kabiven $1540 \mathrm{~mL}$ (Kabiven), SmofKabiven 1477 mL (Smofkabiven), Olimel N9E 1500 mL (Olimel), Nutriflex Omega Special 1875 mL (Nutriflex OS), Nutriflex Lipid Special 1875 mL (Nutriflex LS). The methodology of compatibility studies is not established. According to some researchers' opinions, in drug-PN admixture compatibility tests, it is necessary to determine the physicochemical compatibility (interplay between mixed drugs). The stability of the drug (changes in the drug concentration) can be omitted, as it is assumed to be less critical due to the short contact time of the drug with PN admixture during the Y-site administration $[10,11]$. Following such recommendation, we performed the compatibility studies analyzing changes in $\mathrm{pH}$, osmolarity, mean droplet diameter (MDD) of lipid emulsion, and zeta potential. 
Table 1. Drug-parenteral nutrition admixtures interaction studies.

\begin{tabular}{|c|c|c|}
\hline Compatibility Studies & Conclusions & References \\
\hline $\begin{array}{l}\text { Compatibility studies of Nutriflex Lipid Special and } \\
\text { amoxicillin/clavulanic acid, calcium chloride, cefepime, } \\
\text { cyclosporine, esomeprazole, fentanyl, fluorouracil, } \\
\text { furosemide, magnesium sulfate, meropenem, } \\
\text { metoclopramide, metronidazole, midazolam, morphine } \\
\text { sulfate, noradrenaline, octreotide, ondansetron, } \\
\text { pantoprazole, paracetamol, piperacillin/tazobactam, } \\
\text { potassium phosphate, tacrolimus, } \\
\text { tropisetron, vancomycin }\end{array}$ & $\begin{array}{l}\text { Albumin, esomeprazole, pantoprazole, } \\
\text { tropisetron, and 5-fluorouracil were not } \\
\text { compatible with Nutriflex Lipid Special. }\end{array}$ & $\begin{array}{c}\text { Bouchoud et al., } \\
2013 \text { [4] }\end{array}$ \\
\hline
\end{tabular}

RTU PN admixtures: Olimel N5E and Numeta G16E Drugs: ampicillin, ceftazidime, clindamycin, dexamethasone, fluconazole, fosphenytoin, furosemide, metronidazole, ondansetron, and paracetamol

\section{Compatibility studies of ciprofloxacin and eighteen compounded $\mathrm{PN}$ admixtures for adults}

Compatibility studies of vancomycin and five PN admixtures: Kabiven, Nutriflex Lipid Special, Olimel N9E, Nutriflex Omega Special, and Smofkabiven
Ampicillin, fosphenytoin, and furosemide precipitated when mixed with PN.

Ceftazidime, clindamycin, dexamethasone,

fluconazole, metronidazole, ondansetron and paracetamol were compatible.

Compatibility of ciprofloxacin with PN admixtures depended on drug concentration and calcium and magnesium molar ratio.

Vancomycin was compatible with Kabiven,

Nutriflex Lipid Special, and Nutriflex Omega Special.
Staven et al., 2017 [5]

Gostyńska et al., 2019 [6]

Stawny et al., 2020 [7]

PN and lipid solutions used in a tertiary neonatal unit included a Starter, Standard Preterm and low carbohydrate PN, and SMOFLipid 20\% with Vitalipid N infant and Soluvit $\mathrm{N}$

Drug: ibuprofen lysine

Ibuprofen lysine was compatible with tested $\mathrm{PN}$ admixtures and lipids.
Garcia et al., 2018 [8]

\begin{tabular}{|c|c|c|}
\hline $\begin{array}{l}\text { Compatibility and stability studies of linezolid with six } \\
\text { compounded PN admixtures for adults }\end{array}$ & $\begin{array}{l}\text { Linezolid was compatible and stable with } \\
\text { tested PN admixtures. }\end{array}$ & $\begin{array}{l}\text { Tomczak et al., } \\
2019[9]\end{array}$ \\
\hline $\begin{array}{l}\text { Compatibility and stability studies of levetiracetam with } \\
\text { two compounded PN admixtures for adults }\end{array}$ & $\begin{array}{l}\text { Levetiracetam was compatible and stable } \\
\text { with tested PN admixtures. }\end{array}$ & $\begin{array}{l}\text { Aeberhard et al., } \\
\quad 2017[10]\end{array}$ \\
\hline $\begin{array}{l}\text { Stability studies of ampicillin with two compounded PN } \\
\text { admixtures for adults containing Lipofundin MCT/LCT } \\
\text { or Lipidem }\end{array}$ & $\begin{array}{l}\text { Administration of ampicillin with TPN } \\
\text { admixture at the tested dose is possible when } \\
\text { used ex tempore and with light protection. }\end{array}$ & $\begin{array}{l}\text { Stawny et al., } \\
2019 \text { [11] }\end{array}$ \\
\hline $\begin{array}{l}\text { Compatibility studies of amiodarone with two } \\
\text { compounded PN admixtures for adults containing } \\
\text { Lipofundin MCT/LCT or Smofilipid }\end{array}$ & $\begin{array}{c}\text { Amiodarone was physicochemically } \\
\text { compatible with tested PN admixtures via a } \\
\text { Y-site administration. }\end{array}$ & $\begin{array}{l}\text { Mediavilla et al., } \\
\quad 2019 \text { [12] }\end{array}$ \\
\hline $\begin{array}{l}\text { Compatibility studies of pentoxifylline with six } \\
\text { compounded PN admixtures used in neonatal } \\
\text { intensive care }\end{array}$ & $\begin{array}{l}\text { Pentoxifylline was physicochemically } \\
\text { compatible with six PN admixtures used } \\
\text { in neonatology. }\end{array}$ & $\begin{array}{l}\text { Campbell et al., } \\
\quad 2019 \text { [13] }\end{array}$ \\
\hline $\begin{array}{l}\text { Compatibility studies of dexmedetomidine and three } \\
\text { compounded PN admixtures for adults }\end{array}$ & $\begin{array}{l}\text { Dexmedetomidine was compatible with } \\
\text { tested PN admixtures. }\end{array}$ & $\begin{array}{l}\text { Campos-Baeta et al., } \\
2019 \text { [14] }\end{array}$ \\
\hline $\begin{array}{l}\text { Compatibility studies of amiodarone, caffeine citrate, } \\
\text { clindamycin, enalaprilat, epinephrine, fluconazole, } \\
\text { fosphenytoin sodium, hydrocortisone, metoclopramide, } \\
\text { midazolam, pentobarbital, phenobarbital, and rifampin } \\
\text { with neonatal PN admixtures }\end{array}$ & $\begin{array}{c}\text { Caffeine citrate, clindamycin, enalaprilat, } \\
\text { epinephrine, fluconazole, fosphenytoin } \\
\text { sodium, hydrocortisone, metoclopramide, } \\
\text { and midazolam were compatible with tested } \\
\text { PN admixtures. } \\
\text { Amiodarone, pentobarbital, phenobarbital, } \\
\text { and rifampin were not compatible with the } \\
\text { neonatal TPN solution and should not be } \\
\text { coadministered via Y-site injection. }\end{array}$ & $\begin{array}{l}\text { Fox et al., } \\
2013[15]\end{array}$ \\
\hline
\end{tabular}

\section{Results}

The addition of MPM to PN admixtures did not cause any color changes, signs of lipid emulsion destabilization, or precipitate formation, which two independent observers 
confirmed. The $\mathrm{pH}$ of $\mathrm{PN}$ admixtures did not change significantly after the addition of MPM. For all tested MPM-PN admixture samples, a decrease in $\mathrm{pH}$ was observed, which further decreased after four hours of storage. The maximum $\mathrm{pH}$ reduction at $\mathrm{t}=4 \mathrm{~h}$ was observed for MPM-Olimel 1:1 (change by 0.13 ), while for the remaining samples, the $\mathrm{pH}$ change was not greater than 0.07 . A concentration-dependent decrease in osmolarity was observed, which significantly differed from PN admixtures' osmolarity without the addition of MPM. After four hours of storage, the observed osmolarity changes did not have a directional character and did not exceed $\pm 3 \%$, except for MPM-Olimel samples. In this case, osmolality differences depended on the drug-PN admixtures volume ratio and ranged from $7 \%$ to $11 \%$.

The addition of MPM to PN admixtures reduced the zeta potential, but no linear correlation between MPM concentration and this parameter was found. The physical characteristics of MPM-PN admixture samples are presented in Table 2.

Only in the case of MPM-Olimel (4:1 volume ratio) was the presence of two fractions of lipid emulsion particles observed immediately after sample preparation $(t=0 \mathrm{~h}): \mathrm{dF} 1$ $=282 \pm 6$ and $\mathrm{dF} 2=5170 \pm 9$. At $\mathrm{t}=4 \mathrm{~h}$, the second fraction of lipid emulsion particles was observed for MPM-Olimel samples in 1:1 and 2:1 volume ratios, for MPM-Kabiven, and MPM-Smofkabiven in volume ratios 2:1 and 4:1. The highest percentage of the second fraction of particles (3.1\%) occurred for MPM-Olimel in the 4:1 volume ratio. Simultaneously, a proportional increase in the percentage of dF2 to the MPM concentration in the sample was observed. Interestingly, for all samples, including those with dF2, the MDD was not greater than $500 \mathrm{~nm}$. The dF1 ranged from $220 \mathrm{~nm}$ to $330 \mathrm{~nm}$. The smallest MDD value at $\mathrm{t}=0 \mathrm{~h}$ was recorded for MPM-Nutriflex LS and MPM-Nutriflex OS samples (from $209 \mathrm{~nm} \pm 2 \mathrm{~nm}$ to $212 \mathrm{~nm} \pm 2 \mathrm{~nm}$ and from $215 \mathrm{~nm} \pm 1 \mathrm{~nm}$ to $224 \mathrm{~nm} \pm 2 \mathrm{~nm}$, respectively), and the largest for MPM-Kabiven (from $276 \mathrm{~nm} \pm 5 \mathrm{~nm}$ to $280 \mathrm{~nm} \pm 3 \mathrm{~nm}$ ). The four hours storage of MPM-PN admixtures samples did not cause significant changes in MDD, except the MPM-Olimel samples, for which MDD at $t=4 \mathrm{~h}$ differed significantly $(p<0.05)$ from MDD obtained immediately after receiving the samples. For all MPM-PN admixture samples, the observed polydispersity index (PDI) at $\mathrm{t}=0 \mathrm{~h}$ was $<0.07$ and did not change during storage, except for samples for which the presence of dF2 was observed (PDI increased up to 0.21). The MDD, dF1, dF2, and PDI values are presented in Table 3 .

Table 2. Characteristics of studied parenteral nutrition admixtures containing MPM.

\begin{tabular}{|c|c|c|c|c|c|c|c|}
\hline \multirow{3}{*}{ Sample } & \multirow{3}{*}{$\begin{array}{c}\text { MPM:PN } \\
\text { Ratio }\end{array}$} & \multirow{2}{*}{\multicolumn{2}{|c|}{$\mathbf{p H} \pm \mathbf{S D}$}} & \multirow{2}{*}{\multicolumn{2}{|c|}{$\begin{array}{r}\text { Osmolality } \pm \mathrm{SD} \\
\left(\mathrm{mOsm} / \mathrm{kg} \mathrm{H} \mathrm{H}_{2} \mathrm{O}\right)\end{array}$}} & \multirow{2}{*}{\multicolumn{2}{|c|}{$\begin{array}{c}\text { Zeta Potential } \pm \text { SD } \\
(\mathrm{mV})\end{array}$}} \\
\hline & & & & & & & \\
\hline & & $\mathbf{O h}$ & $4 h^{*}$ & $\mathbf{O H}$ & $4 \mathrm{~h}$ & $\mathbf{O h}$ & $4 \mathrm{~h}$ \\
\hline \multirow{3}{*}{ MPM-Kabiven } & $1: 1$ & $6.70 \pm 0.00$ & $6.66 \pm 0.00$ & $672 \pm 1$ & $685 \pm 1$ & $-19.0 \pm 0.8$ & $-19.2 \pm 0.7$ \\
\hline & $2: 1$ & $7.07 \pm 0.01$ & $7.06 \pm 0.01$ & $528 \pm 3$ & $541 \pm 4$ & $-25.3 \pm 1.1$ & $-23.0 \pm 0.8$ \\
\hline & $4: 1$ & $7.37 \pm 0.01$ & $7.32 \pm 0.00$ & $440 \pm 3$ & $437 \pm 4$ & $-25.6 \pm 0.3$ & $-25.9 \pm 0.3$ \\
\hline \multirow{3}{*}{$\begin{array}{c}\text { MPM-Nutriflex } \\
\text { LS }\end{array}$} & $1: 1$ & $6.47 \pm 0.00$ & $6.43 \pm 0.00$ & $977 \pm 5$ & $947 \pm 4^{* *}$ & $-26.8 \pm 1.6$ & $-27.0 \pm 1.2$ \\
\hline & $2: 1$ & $6.89 \pm 0.00$ & $6.86 \pm 0.00$ & $710 \pm 3$ & $725 \pm 3^{* *}$ & $-32.8 \pm 1.1$ & $-32.2 \pm 0.3$ \\
\hline & $4: 1$ & $7.20 \pm 0.00$ & $7.17 \pm 0.01$ & $546 \pm 4$ & $542 \pm 5$ & $-34.9 \pm 1.1$ & $-32.5 \pm 0.7$ \\
\hline \multirow{3}{*}{ MPM-Olimel } & $1: 1$ & $6.98 \pm 0.00$ & $6.85 \pm 0.01$ & $805 \pm 11$ & $892 \pm 5^{* *}$ & $-20.6 \pm 1.2$ & $-32.1 \pm 1.6^{* *}$ \\
\hline & $2: 1$ & $7.22 \pm 0.00$ & $7.19 \pm 0.00$ & $630 \pm 6$ & $673 \pm 4^{* *}$ & $-20.1 \pm 1.4$ & $-31.8 \pm 5.9^{* *}$ \\
\hline & $4: 1$ & $7.42 \pm 0.01$ & $7.35 \pm 0.01$ & $476 \pm 1$ & $516 \pm 4^{* *}$ & $-20.4 \pm 0.6$ & $-32.0 \pm 3.6^{* *}$ \\
\hline \multirow{3}{*}{$\begin{array}{c}\text { MPM-Nutriflex } \\
\text { OS }\end{array}$} & $1: 1$ & $6.44 \pm 0.01$ & $6.37 \pm 0.00$ & $957 \pm 8$ & $986 \pm 1$ ** & $-14.8 \pm 0.4$ & $-14.0 \pm 0.3$ \\
\hline & $2: 1$ & $6.85 \pm 0.00$ & $6.8 \pm 0.00$ & $731 \pm 1$ & $749 \pm 1$ ** & $-19.2 \pm 0.8$ & $-22.0 \pm 0.2$ \\
\hline & $4: 1$ & $7.15 \pm 0.01$ & $7.12 \pm 0.01$ & $549 \pm 0$ & $552 \pm 0$ & $-14.2 \pm 0.9$ & $-12.9 \pm 0.2$ \\
\hline \multirow{3}{*}{$\begin{array}{c}\text { MPM- } \\
\text { Smofkabiven }\end{array}$} & $1: 1$ & $6.41 \pm 0.00$ & $6.37 \pm 0.01$ & $901 \pm 3$ & $902 \pm 2$ & $-21.2 \pm 0.6$ & $-16.3 \pm 0.4^{* *}$ \\
\hline & $2: 1$ & $6.87 \pm 0.01$ & $6.85 \pm 0.01$ & $688 \pm 4$ & $675 \pm 3^{* *}$ & $-23.5 \pm 0.9$ & $-20.5 \pm 1.1$ \\
\hline & $4: 1$ & $7.23 \pm 0.01$ & $7.16 \pm 0.01$ & $514 \pm 3$ & $505 \pm 3$ & $-24.1 \pm 1.4$ & $-20.7 \pm 0.8$ \\
\hline
\end{tabular}

SD—standard deviation; *-all $\mathrm{pH}$ results obtained after $4 \mathrm{~h}$ of storage were significantly different from $\mathrm{t}=0 \mathrm{~h}$ values $(p<0.05) ;{ }^{* *}$-values obtained after $4 \mathrm{~h}$ of storage were significantly different from $\mathrm{t}=0 \mathrm{~h}$ values $(p<0.05)$. 
Table 3. Lipid droplet characteristics of studied parenteral nutrition admixtures containing meropenem (MPM).

\begin{tabular}{|c|c|c|c|c|c|c|c|c|}
\hline \multirow{3}{*}{ Sample } & \multirow{3}{*}{$\begin{array}{c}\text { MPM:PN } \\
\text { Ratio }\end{array}$} & \multirow{3}{*}{$\begin{array}{c}\mathrm{PDI} \pm \mathrm{SD} \\
4 \mathrm{~h}\end{array}$} & \multicolumn{2}{|c|}{$\mathrm{MDD} \pm \mathrm{SD}$} & \multirow{2}{*}{\multicolumn{2}{|c|}{$\begin{array}{l}\mathrm{dF1} \pm \mathrm{SD} \\
(\mathrm{nm})\end{array}$}} & \multicolumn{2}{|c|}{$\mathrm{dF} 2 \pm \mathrm{SD}$} \\
\hline & & & & & & & & \\
\hline & & & $0 \mathrm{~h}$ & $4 \mathrm{~h}$ & $0 \mathrm{~h}$ & $4 \mathrm{~h}$ & $0 \mathrm{~h}$ & $4 \mathrm{~h}$ \\
\hline \multirow{3}{*}{$\begin{array}{c}\text { MPM- } \\
\text { Kabiven }\end{array}$} & $1: 1$ & $0.05 \pm 0.02$ & $280.2 \pm 3.2$ & $280.2 \pm 7.2$ & $319.6 \pm 4.2$ & $319.6 \pm 6.5$ & n.d. & n.d. \\
\hline & $2: 1$ & $0.17 \pm 0.01$ & $275.9 \pm 4.5$ & $275.9 \pm 7.0$ & $320.8 \pm 3.7$ & $320.7 \pm 4.3$ & n.d. & $4687 \pm 7$ \\
\hline & $4: 1$ & $0.18 \pm 0.01$ & $277.8 \pm 6.2$ & $277.8 \pm 6.3$ & $326.9 \pm 4.2$ & $326.9 \pm 6.2$ & n.d. & $4972 \pm 5$ \\
\hline \multirow{3}{*}{$\begin{array}{l}\text { MPM- } \\
\text { Nutriflex } \\
\text { LS }\end{array}$} & $1: 1$ & $0.06 \pm 0.03$ & $212.4 \pm 2.2$ & $212.4 \pm 2.3$ & $228.6 \pm 2.3$ & $228.6 \pm 2.9$ & n.d. & n.d. \\
\hline & $2: 1$ & $0.07 \pm 0.02$ & $211.1 \pm 1.9$ & $208.3 \pm 2.5$ & $228.2 \pm 2.1$ & $227.8 \pm 3.3$ & n.d. & n.d. \\
\hline & $4: 1$ & $0.05 \pm 0.02$ & $208.7 \pm 2.5$ & $208.7 \pm 2.2$ & $221.9 \pm 3.4$ & $221.9 \pm 3.7$ & n.d. & n.d. \\
\hline \multirow{3}{*}{ MPM-Olimel } & $1: 1$ & $0.16 \pm 0.04$ & $256.6 \pm 1.4$ & $266.8 \pm 7.6^{* *}$ & $281.9 \pm 5.8$ & $296.2 \pm 5.4$ & n.d. & $5064 \pm 9$ \\
\hline & $2: 1$ & $0.18 \pm 0.01$ & $254.4 \pm 2.8$ & $266.1 \pm 4.6$ & $281.4 \pm 2.0$ & $296.2 \pm 4.7$ & n.d. & $5190 \pm 8$ \\
\hline & $4: 1$ & $0.21 \pm 0.01$ & $253.0 \pm 2.6$ & $262.8 \pm 7.2$ & $283.2 \pm 8.1$ & $282.4 \pm 6.2$ & $5170 \pm 9$ & $5389 \pm 12$ \\
\hline \multirow{3}{*}{$\begin{array}{l}\text { MPM- } \\
\text { Nutriflex } \\
\text { OS }\end{array}$} & $1: 1$ & $0.07 \pm 0.01$ & $223.8 \pm 1.7$ & $220.9 \pm 2.5$ & $247.2 \pm 1.3$ & $238.4 \pm 6.1$ & n.d. & n.d. \\
\hline & $2: 1$ & $0.08 \pm 0.02$ & $215.1 \pm 1.3$ & $216.4 \pm 2.4$ & $234.6 \pm 4.3$ & $238.2 \pm 7.3$ & n.d. & n.d. \\
\hline & $4: 1$ & $0.06 \pm 0.03$ & $218.6 \pm 1.2$ & $219.5 \pm 3.9$ & $236.2 \pm 7.6$ & $239.7 \pm 4.5$ & n.d. & n.d. \\
\hline \multirow{3}{*}{$\begin{array}{c}\text { MPM- } \\
\text { Smofkabiven }\end{array}$} & $1: 1$ & $0.06 \pm 0.01$ & $237.1 \pm 2.4$ & $236.4 \pm 2.1$ & $272.8 \pm 7.2$ & $263.2 \pm 3.0$ & n.d. & n.d. \\
\hline & $2: 1$ & $0.15 \pm 0.01$ & $234.5 \pm 1.3$ & $233.9 \pm 0.4$ & $258.1 \pm 3.7$ & $257.4 \pm 4.6$ & n.d. & $4996 \pm 8$ \\
\hline & $4: 1$ & $0.16 \pm 0.01$ & $234.0 \pm 2.5$ & $232.0 \pm 0.2$ & $265.4 \pm 3.5$ & $255.0 \pm 4.3$ & n.d. & $5151 \pm 10$ \\
\hline
\end{tabular}

SD—standard deviation; dF1—first fraction of lipid emulsion particles; dF2—second fraction of lipid emulsion particles n.d.—not detected;

**-values obtained after $4 \mathrm{~h}$ of storage were significantly different from $\mathrm{t}=0 \mathrm{~h}$ values $(p<0.05)$.

\section{Discussion}

So far, the MPM and PN admixtures' compatibility tests were undertaken by two groups of researchers [4,19]. Trissel et al. [19] showed that MPM is compatible with the nine compounded PN admixtures. According to their research methodology, the compatibility was proven by lack of visible particles, lack of oiling (formation of a layer of free oil on the top of a disrupted lipid emulsion layer), cracking, creaming, color change, or gas evolution. Bouchoud et al. [4] determined MPM compatibility at a concentration of $50 \mathrm{mg} / \mathrm{mL}$ (bolus administration) with Nutriflex LS. As acceptance criteria, the researchers adopted: change in $\mathrm{pH} \leq 0.2$, no lipid droplets $>15 \mu \mathrm{m}$ visible in five microscopic images, not more than 90 lipid droplets from $2-15 \mu \mathrm{m}$ in size in five microscopic images, changes of MDD during storage $<10 \%$, and PFAT5 $<0.04 \%$ (PFAT5: the percentage of fat residing in globules larger than $5 \mu \mathrm{m})$. MPM-Nutriflex LS in a 1:1 volume ratio met these criteria and was found to be compatible.

Our research used MPM solution in a concentration of $8.33 \mathrm{mg} / \mathrm{mL}(1000 \mathrm{mg}$ MPM dissolved in $120 \mathrm{~mL}$ of $0.9 \%$ sodium chloride), which was administrated in clinical practice in 30-60 min infusion. We mixed each of the PN admixtures with MPM in three-volume ratios $(1: 1,2: 1$, and 4:1), which simulated the coadministration of those drugs via Y-site. The mixing ratios were calculated based on both preparations' infusion rates, i.e., the drug and the PN admixture. It should be emphasized that the time of infusion of MPM and $\mathrm{PN}$ admixture lasts $15-30 \mathrm{~min}$ and 16 to $24 \mathrm{~h}$, respectively. The time of coexisting of both drugs in the infusion line can be counted in minutes. The exact time of contact can be calculated on the basis of the infusion rates of co-infused drugs, the volume of the infusion line, and the placement of Y-site in the infusion line. In this study, two endpoints were applied, namely, immediately after preparation and after $4 \mathrm{~h}$, in order to fully characterize the potential incompatibilities of the studied drugs during infusion. The second endpoint (four hours) was chosen to characterize possible interactions in case of any infusion time variation or the volume of the infusion line.

The following criteria were set to consider the MPM-PN admixture samples as compatible: $\mathrm{pH}$ change not greater than \pm 0.2 (after $4 \mathrm{~h}$ of storage), osmolarity change not greater than $\pm 5 \%$ (after $4 \mathrm{~h}$ of storage), difference in zeta potential not greater than $\pm 3 \mathrm{mV}$ 
(after $4 \mathrm{~h}$ of storage), lack of the second fraction of lipid particles $>1000 \mathrm{~nm}$, and following United States Pharmacopoeia (USP), the MDD of lipid emulsion $<500 \mathrm{~nm}$ [20].

The $\mathrm{pH}$ changes for all MPM-PN admixture samples did not exceed the assumed level of acceptability. The amino acid solution used to prepare PN admixtures had a high buffering capacity, further increased by acetates. The addition of drugs that are weak acids or bases to PN admixtures may cause precipitation of the drug due to a change in $\mathrm{pH}$ and the transition of the drug from the ionized form to the nonionized one. Such a phenomenon was observed, for example, for ondansetron, whose solubility decreases at $\mathrm{pH}>5.7$ [21]. The tested MPM solution was characterized by $\mathrm{pH}=8.03$, and adjusting to $\mathrm{pH} 5.0 \mathrm{did}$ not cause precipitation or opalescence of the solution. Similarly, no signs of precipitation were observed after mixing MPM with PN admixtures, with $\mathrm{pH}$ ranging from 5.44 to 6.26.

Osmolarity changes after four hours of storage of MPM-PN admixture samples were $\pm 3 \%$, except MPM-Olimel samples, for which differences from $7 \%$ to $11 \%$ were observed. Similar changes in osmolarity were observed for vancomycin-Olimel samples [7], suggesting that osmotically active ingredients are involved in drug-Olimel interactions or that metal ions are involved in the formation of lipid emulsion-drug complexes. The osmolarity of PN admixtures was $>1000 \mathrm{mOsm} / \mathrm{kg}$. Thus, the coadministration of compatible preparations should be provided into the central veins. Administration of hyperosmolar drug into peripheral veins leads to dehydration and contraction of blood cells and damage of blood vessels (phlebitis) [22].

The determination of the zeta potential, which is the potential difference between the dispersion medium and the stationary layer of fluid attached to the particle, allows evaluation of the strength of electrostatic interactions between particles in a PN admixture. The zeta potential depends on the electrolyte concentration and the $\mathrm{pH}$ of the sample. It was shown that lipid emulsions used in PN, due to stabilizing phospholipids, are characterized by a zeta potential of -40 to $-50 \mathrm{mV}$, thus exhibiting substantial stability. Depending on the TPN admixtures' composition, the zeta potential may even have values close to zero, in a range of -4.1 to $-1.7 \mathrm{mV}$ [5-7].

The zeta potential of MPM-PN samples at $t=0 \mathrm{~h}$ depended on the type of lipid emulsion, PN admixture composition, and MPM concentration. Zeta potential of MPM-PN samples ranged from $-14.20 \mathrm{mV}$ (MPM-Nutriflex OS in 4:1 ratio) to $-34.90 \mathrm{mV}$ (MPMNutriflex LS in 4:1 ratio). The adopted level of acceptability of changes in zeta potential after four hours of storage $( \pm 3 \mathrm{mV})$ was met for MPM-Kabiven, MPM-Nutriflex LS, and MPM-Nutriflex OS. For the remaining MPM-PN admixture samples (MPM-Olimel and MPM-Smofkabiven), the differences were above the acceptable limit and ranged from $3.00 \mathrm{mV}$ to $11.70 \mathrm{mV}$. These observations suggested the dynamic impact of MPM on the strength of electrostatic interactions between lipid droplets in a PN admixture.

Lipid emulsions used in parenteral nutrition are oil-in-water $(o / w)$ system characterizing by a particle size between 200 and $400 \mathrm{~nm}$ and exhibit thermodynamic instability. Factors such as temperature above $25^{\circ} \mathrm{C}$, high concentration of cations (critical aggregates concentration, CAN > 600), and exposure to oxygen may affect the stability of the $o / w$ emulsion. The first stage of destabilization of such product is creaming, manifested by thickening of the upper layer due to the formation of larger aggregates with or without increasing the mean particle size. The next stage of destabilization of the lipid emulsion is coalescence, i.e., the release of oil drops resulting from exceeding the critical values, maintaining electrostatic differences between the inner and outer micelle layers. This step is irreversible and cracks the emulsion. The destabilization processes of the lipid emulsion may also be accompanied by a change in color, usually yellowing, due to oxidation of free fatty acids and the formation of reactive peroxides. These types of reactions are radical and initiate drug decomposition. An intravenous administration of such preparations may cause the intensification of inflammation due to intravenous administration of free radicals. Both the destabilization process of the lipid emulsion and reactive oxygen species formation may affect the lipid emulsion particles' size. In the event of agglomerate formation, it may directly threaten patients and lead to capillary embolization. 
Lipid emulsion droplet size is one of the most critical parameters that should be considered when determining PN admixture administration safety. US Pharmacopoeia [20] gives two methods for determining the size of lipid emulsion droplets, namely, the method using the dynamic light scattering (DLS) technique, for which MDD should not be greater than $500 \mathrm{~nm}$, and a method based on light obscuration, for which large-diameter droplets $(>5 \mu \mathrm{m}$ ) of lipid emulsions should not exceed $0.05 \%$. Our research used the first method to determine MDD and adopted an acceptable value of $500 \mathrm{~nm}$, following USP recommendations. Additionally, we introduced a second acceptance parameter, i.e., no second fraction of particle $>1000 \mathrm{~nm}$. The second fraction of lipid particles of larger size $(\sim 5 \mu \mathrm{m})$ in parenteral nutrition poses a risk to patients, as pulmonary embolism may occur. Animal studies showed that fat droplets size about $5 \mu \mathrm{m}$ cause harm to the lungs and liver [21]. MDD was below $500 \mathrm{~nm}$; however, only two of the tested PN admixtures (Nutriflex LS and Nutriflex OS) did not form the second fraction of lipid emulsion particles after MPM addition. In the case of MPM-Olimel samples in a 4:1 volume ratio, the second fraction of particles was observed immediately after sample preparation and after four hours of storage, indicating that MPM affects lipid emulsion. At $t=4 \mathrm{~h}$, the second fraction of lipid emulsion particles was also observed for MPM-Olimel 1:1 $(v / v)$ and 2:1 $(v / v)$ and for all samples of MPM-Kabiven and MPM-Smofkabiven. The reason for the formation of larger droplets of lipid emulsion is most likely the type of lipid emulsion (fatty acids composition) and the number of emulsifiers used. The size of the large lipid droplets formed and their content depends on the sample's MPM concentration. For all MPM-PN admixture samples, for which the presence of the second fraction of particles $>1000 \mathrm{~nm}$ was observed, the PDIs were $>0.1$, indicating a decrease in the homogeneity of the oil-in-water system. The summary of conducted investigations is presented in Figure 1.

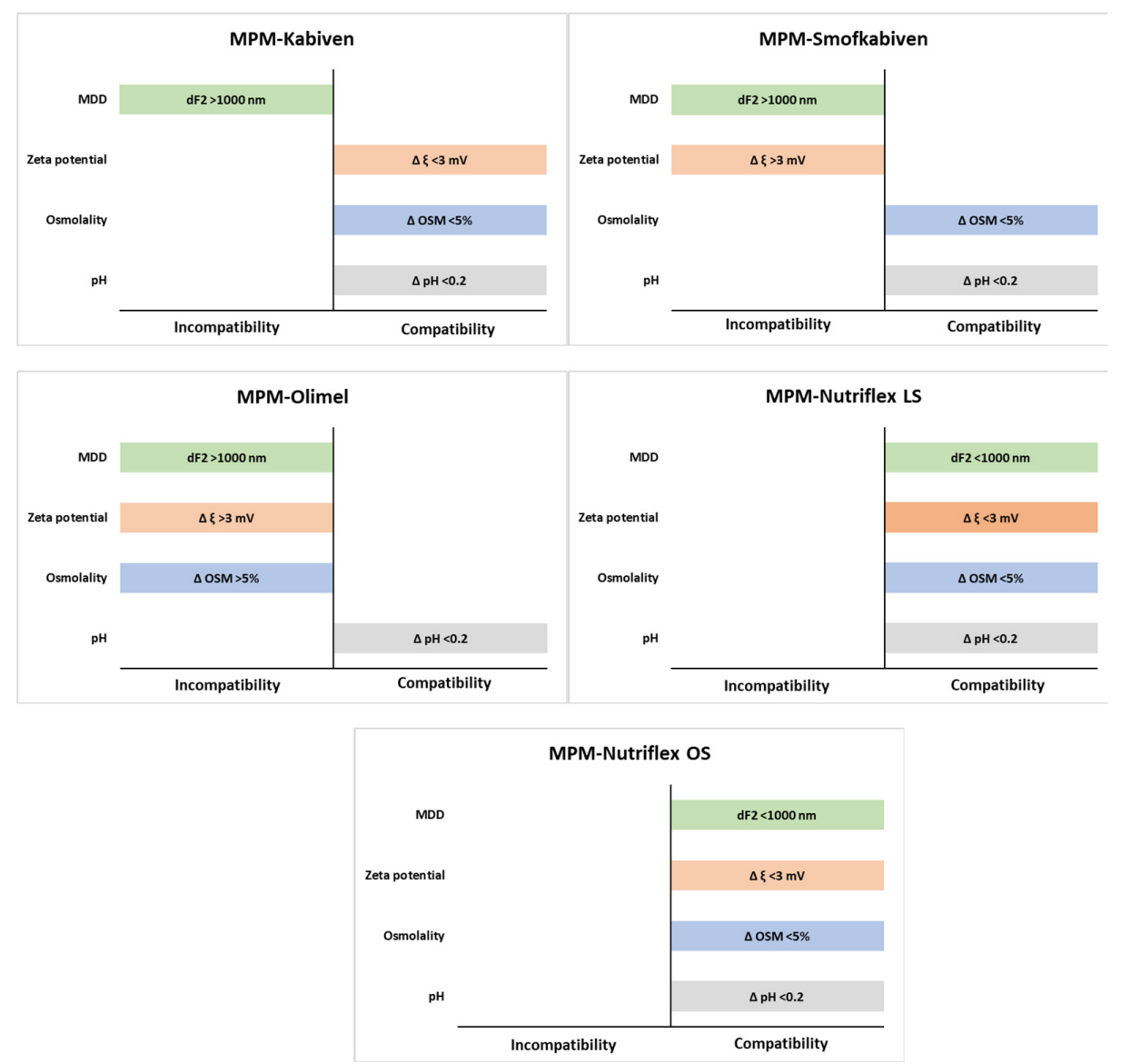

Figure 1. Summary of compatibility studies of MPM and parenteral nutrition admixtures. 


\section{Materials and Methods}

\subsection{Sample Preparation}

MPM solution (Meropenem 1000, Pfizer Europe) was prepared by adding $20.0 \mathrm{~mL}$ of water for injection to the vial containing $1000 \mathrm{mg}$ of MPM. A total of $4.17 \mathrm{~mL}$ of solution was withdrawn and transferred to $25 \mathrm{~mL}$ of $0.9 \%$ sodium chloride solution. The MPM concentration was $8.34 \mathrm{mg} / \mathrm{mL}$.

Five ready-to-use PN admixtures were used in this study: Kabiven $1540 \mathrm{~mL}$ (Kabiven), Fresenius Kabi AB, Uppsala, Sweden; SmofKabiven 1477 mL (Smofkabiven), Fresenius Kabi AB, Sweden; Olimel N9E 1500 mL (Olimel) Baxter, Poland; Nutriflex Omega Special $1875 \mathrm{~mL}$ (Nutriflex OS) B. Braun Melsungen AG, Melsungen, Germany; and Nutriflex Lipid Special $1875 \mathrm{~mL}$ (Nutriflex LS) B. Braun Melsungen AG, Germany. The detailed characteristics of the PN admixtures are presented in Table 4.

Each PN admixture was prepared according to the manufacturer's instructions, and then vitamins and trace elements were added. The Cernevit (Baxter, Poland) and Tracutil were added to Olimel, Nutriflex LS, and Nutriflex OS. The Soluvit N (Fresenius Kabi AB, Sweden) was dissolved in Vitalipid N Adult (Fresenius Kabi AB, Sweden), and such vitamin emulsion was added to Kabiven and Smofkabiven together with Addamel N (Fresenius Kabi AB, Sweden).

Based on the summary medicinal product characteristics, the infusion time for MPM and PN admixtures was determined. The volume ratios of the MPM and PN admixture in the infusion line were obtained by dividing the drug infusion rate by the PN admixture infusion rate. The calculated MPM:PN volume ratios used in the study were 1:1; 2:1, and $4: 1$.

\subsection{Physicochemical Stability Assessment}

Physical stability studies of PN admixtures included a visual examination and determination of $\mathrm{pH}$, osmolarity, MDD of lipid emulsion, and zeta potential. All measurements were performed in triplicate for PN admixtures and MPM-PN admixture samples and expressed as mean \pm standard deviation.

According to the European Pharmacopoeia [23], all samples were visually assessed against a black-and-white contrast background by two observers for lack of visible particles and color changing. The evaluation of $\mathrm{pH}$ was performed using $\mathrm{pH}$-meter Seven Compact $\mathrm{pH} /$ ion S220 (Mettler Toledo, Greifensee, Switzerland). The MDD of lipid emulsion and zeta potential of PN admixtures were measured using Zetasizer Nano ZS (Malvern Instruments, Malvern, UK) at $25^{\circ} \mathrm{C}$ according to US Pharmacopoeia [20]. The osmolarity was measured at room temperature using an $800 \mathrm{CL}$ TridentMed ${ }^{\circledR}$ osmometer (Trident Med s.c., Warsaw, Poland).

Samples for particle size and zeta potential measurement were prepared following the same procedure, where $1 \mathrm{~mL}$ of MPM-PN admixture samples was diluted 10 times with water for injection. Then, $1 \mathrm{~mL}$ of diluted sample was transferred to a measurement cell for particle size and zeta potential determination, using DLS and laser Doppler electrophoresis (LDE) methods, respectively.

\subsection{Acceptance Limits}

To consider PN admixtures as compatible with MPM, the following criteria must be met: practically free from visible particles, no turbidity or precipitation may be detected by any of observers upon visual inspection, changes in $\mathrm{pH}$ after four hours of storage $(\Delta \mathrm{pH})<0.2$, changes in osmolarity after four hours of storage $(\Delta \mathrm{OSM})<5 \%$, changes in zeta potential after four hours of storage $(\Delta \xi)<3 \mathrm{mV}$, the size of lipid droplets expressed as intensity-weighted MDD can not exceed the pharmacopeial limit of $500 \mathrm{~nm}$, and no second fraction (dF2) of lipid droplets $>1000 \mathrm{~nm}$. 
Table 4. Composition of tested parenteral nutrition admixtures.

\begin{tabular}{|c|c|c|c|c|c|}
\hline & Kabiven & Nutriflex LS & Olimel & Nutriflex OS & SmofKabiven \\
\hline & \multicolumn{5}{|c|}{$\mathrm{g} / 1000 \mathrm{~mL}$} \\
\hline Alanine & 4.7 & 6.8 & 8.3 & 6.8 & 7.1 \\
\hline Arginine & 3.3 & 3.8 & 5.6 & 3.8 & 6.1 \\
\hline Aspartic acid & 1.0 & 2.1 & 1.7 & 2.1 & - \\
\hline Glutamic acid & 1.6 & 4.9 & 2.9 & 4.9 & - \\
\hline Glicyne & 2.3 & 2.3 & 3.9 & 2.3 & 5.6 \\
\hline Histidine & 2.0 & 1.8 & 3.4 & 1.8 & 1.5 \\
\hline Izoleucine & 1.6 & 3.3 & 2.9 & 3.3 & 2.6 \\
\hline Leucine & 2.3 & 4.4 & 3.9 & 4.4 & 3.8 \\
\hline Lisyne & 2.7 & 3.2 & 4.5 & 3.2 & 3.4 \\
\hline Methionine & 1.6 & 2.7 & 2.9 & 2.7 & 2.2 \\
\hline Phenylalanine & 2.3 & 4.9 & 3.9 & 4.9 & 2.6 \\
\hline Proline & 2.0 & 4.7 & 3.4 & 4.7 & 5.7 \\
\hline Serine & 1.3 & 4.2 & 2.3 & 4.2 & 3.3 \\
\hline Taurine & - & - & - & - & 0.54 \\
\hline Threonine & 1.6 & 2.6 & 2.9 & 2.6 & 2.2 \\
\hline Tryptophan & 0.6 & 0.8 & 0.9 & 0.8 & 1.0 \\
\hline Tyrosine & 0.1 & - & 0.1 & & 0.2 \\
\hline Valine & 2.1 & 3.6 & 3.7 & 3.6 & 3.1 \\
\hline Total amino acids & 33.1 & 56.1 & 56.9 & 56.1 & 50.8 \\
\hline Nitrogen & 5.3 & 8.0 & 9.0 & 8.0 & 8.1 \\
\hline Glucose & 97.4 & 144.0 & 110.0 & 144.0 & 126.6 \\
\hline LCT & 39.0 & 20.0 & 8.0 & 20.0 & 11.4 \\
\hline MCT & - & 20.0 & - & 16.0 & 11.4 \\
\hline Olive oil & - & - & 32.0 & - & 9.5 \\
\hline Omega-3 acids & - & - & - & 4.0 & 5.7 \\
\hline \multirow[t]{2}{*}{ Total lipids } & 39.0 & 40.0 & 40.0 & 40.0 & 38.1 \\
\hline & \multicolumn{5}{|c|}{$\mathrm{mmol} / 1000 \mathrm{~mL}$} \\
\hline Sodium & 31.2 & 53.6 & 35.0 & 53.6 & 40.6 \\
\hline Potassium & 23.4 & 37.6 & 30.0 & 37.6 & 30.5 \\
\hline Magnesium & 3.9 & 4.2 & 4.0 & 4.2 & 5.1 \\
\hline Calcium & 1.9 & 4.2 & 3.5 & 4.2 & 2.6 \\
\hline Zinc & - & 0.032 & - & 0.032 & 0.041 \\
\hline Chlorides & 45.5 & 48.0 & 45.3 & 48.0 & 35.2 \\
\hline Phosphates & 37.7 & 16.0 & 15.0 & 16.0 & 12.9 \\
\hline Acetates & 9.7 & 48.0 & 53.3 & 48.0 & 106.3 \\
\hline
\end{tabular}

\subsection{Statistical Analysis}

The data were analyzed using Statistica 12 software (StatSoft, Cracow, Poland). Twoway analysis of variance (ANOVA) was used to determine the statistical significance occurring among the samples. The a priori level of significance was $p<0.05$. In the case of a major effect or interaction, significant differences between the samples in $\mathrm{t}=0 \mathrm{~h}$ and 
samples in $\mathrm{t}=4 \mathrm{~h}$ were identified using Tukey's honest significant difference (HSD) post hoc tests.

\section{Conclusions}

The assumed acceptance criteria for MPM compatibility with PN admixtures were met only for Nutriflex LS and Nutriflex OS in 1:1, 2:1, and 4:1 volume ratios. At the same time, the obtained results do not allow recommending coadministration of MPM via Y-site with Kabiven, Olimel, and Smofkabiven due to osmolarity fluctuations (MPM-Olimel), significant differences in zeta potential (MPM-Olimel, MPM-Smofkabiven), and the presence of the second fraction of particles $>1000 \mathrm{~nm}$ (MPM-Kabiven, MPM-Olimel, and MPM-Smofkabiven).

Author Contributions: Conceptualization, A.G. and M.S.; methodology, A.G. and M.S.; software, M.N.; formal analysis, M.N., M.O., M.P.-B., and L.P.; investigation, M.P.-B., M.O., M.N., and L.P.; writing—original draft preparation, A.G., M.S., and K.D.; writing—review and editing, A.J.; supervision, A.J.; project administration, M.S. and K.D. All authors have read and agreed to the published version of the manuscript.

Funding: This research was funded by National Science Centre, Poland, grant SONATA no. 2015/17/ D/NZ7/00792.

Data Availability Statement: Data is contained within the article.

Conflicts of Interest: The authors declare no conflict of interest.

\section{References}

1. Pinelli, F.; Cecero, E.; Degl'Innocenti, D.; Selmi, V.; Giua, R.; Villa, G.; Chelazzi, C.; Romagnoli, S.; Pittiruti, M. Infection of totally implantable venous access devices: A review of the literature. J. Vasc. Access 2018, 19, 230-242. [CrossRef]

2. Kanji, S.; Lam, J.; Johanson, C.; Singh, A.; Goddard, R.; Fairbairn, J.; Lloyd, T.; Monsour, D.; Kakal, J. Systematic review of physical and chemical compatibility of commonly used medications administered by continuous infusion in intensive care units. Crit. Care Med. 2010, 38, 1890-1898. [CrossRef]

3. Taxis, K.; Barber, N. Ethnographic study of incidence and severity of intravenous drug errors. BMJ 2003, 326, 684-687. [CrossRef]

4. Bouchoud, L.; Fonzo-Christe, C.; Klingmüller, M.; Bonnabry, P. Compatibility of intravenous medications with parenteral nutrition: In vitro evaluation. J. Parenter. Enteral Nutr. 2013, 37, 416-424. [CrossRef]

5. Staven, V.; Iqbal, H.; Wang, S.; Grønlie, I.; Tho, I. Physical compatibility of total parenteral nutrition and drugs in Y-site administration to children from neonates to adolescents. J. Pharm. Pharmacol. 2017, 69, 448-462. [CrossRef]

6. Gostyńska, A.; Stawny, M.; Dettlaff, K.; Jelińska, A. The Interactions between Ciprofloxacin and Parenteral Nutrition Admixtures. Pharmaceutics 2020, 12, 27. [CrossRef]

7. Stawny, M.; Nadolna, M.; Jelińska, A. In vitro compatibility studies of vancomycin with ready-to-use parenteral nutrition admixtures for safer clinical practice. Clin. Nutr. 2020, 39, 2539-2546. [CrossRef]

8. Garcia, J.; Garg, A.; Song, Y.; Fotios, A.; Andersen, C.; Garg, S. Compatibility of intravenous ibuprofen with lipids and parenteral nutrition, for use as a continuous infusion. PLoS ONE 2018, 13, e0190577. [CrossRef]

9. Tomczak, S.; Stawny, M.; Dettlaff, K.; Kieliszek, M.; Słomińska, D.; Jelińska, A. Physicochemical compatibility and stability of linezolid with parenteral nutrition. Molecules 2019, 24, 1242. [CrossRef] [PubMed]

10. Aeberhard, C.; Steuer, C.; Saxer, C.; Huber, A.; Stanga, Z.; Mühlebach, S. Physicochemical stability and compatibility testing of levetiracetam in all-in-one parenteral nutrition admixtures in daily practice. Eur. J. Pharm. Sci. 2017, 96, 449-455. [CrossRef] [PubMed]

11. Stawny, M.; Gostyńska, A.; Dettlaff, K.; Jelińska, A.; Główka, E.; Ogrodowczyk, M. Effect of lipid emulsion on stability of ampicillin in total parenteral nutrition. Nutrients 2019, 11, 559. [CrossRef]

12. Mediavilla, M.M.; Molina, A.; Navarro, L.; Grau, L.; Pujol, M.D.; Cardenete, J.; Cardona, D.; Riera, P. Physicochemical compatibility of amiodarone with parenteral nutrition. J. Parenter. Enter Nutr. 2018, 43, 298-304. [CrossRef] [PubMed]

13. Campbell, A.L.; Petrovski, M.; Senarathna, S.G.; Mukadam, N.; Strunk, T.; Batty, K.T. Compatibility of pentoxifylline and parenteral medications. Arch. Dis. Child 2020, 105, 395-397.

14. Campos-Baeta, Y.; Saavedra-Mitjans, M.; Garin, N.; Cardenete, J.; Cardona, D.; Riera, P. Physicochemical compatibility of dexmedetomidine with parenteral nutrition. Nutr. Clin. Pract. 2020, 35, 967-972. [CrossRef] [PubMed]

15. Fox, L.M.; Wilder, A.G.; Foushee, J.A. Physical compatibility of various drugs with neonatal total parenteral nutrient solution during simulated Y-site administration. Am. J. Health Syst. Pharm. 2013, 70, 520-524. [CrossRef]

16. Stawny, M.; Olijarczyk, R.; Jaroszkiewicz, E.; Jelińska, A. Pharmaceutical point of view on parenteral nutrition. Sci. World J. 2013, 2013, 1-9. [CrossRef] [PubMed] 
17. Trissel, L.A. Everything in a compatibility study is important. Am. J. Health Syst. Pharm. 1996, 53, 2990. [CrossRef] [PubMed]

18. Husson, E.; Crauste-Manciet, S.; Hadj-Salah, E.; Seguier, J.C.; Brossard, D. Compatibility of parenteral drugs with commercialized total parenteral admixtures during simulated Y-site infusion. Nutr. Clin. Metabol. 2003, 17, 72-79. [CrossRef]

19. Trissel, L.A.; Gilbert, D.L.; Martinez, J.F.; Baker, M.B.; Walter, W.V.; Mirtallo, J.M. Compatibility of medications with 3-in-1 parenteral nutrition admixtures. J. Parenter. Enter Nutr. 1999, 23, 67-74. [CrossRef]

20. The United States Pharmacopeia and National Formulary, 38th ed.; United States Pharmacopeial Convention: Rockville, MD, USA, 2015.

21. Staven, V.; Wang, S.; Grønlie, I.; Tho, I. Development and evaluation of a test program for Y-site compatibility testing of total parenteral nutrition and intravenous drugs. Nutr. J. 2016, 15, 29. [CrossRef]

22. Wang, W. Tolerability of hypertonic injectables. Int. J. Pharm. 2015, 490, 308-315. [CrossRef] [PubMed]

23. European Directorate for Quality in Medicines and Healthcare (EDQM). European Pharmacopoeia 9.0; 2.9.20. Particulate Contamination: Visible Particles; EDQM: Strasburg, France, 2017. 